\title{
Pulmonary artery pressure measurement during exercise testing in patients with suspected pulmonary hypertension
}

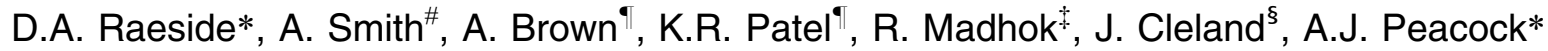

\begin{abstract}
Pulmonary artery pressure measurement during exercise testing in patients with suspected pulmonary hypertension. D.A. Raeside, A. Smith, A. Brown, K.R. Patel, R. Madhok, J. Cleland, A.J. Peacock. C ERS Journals Ltd 2000.

ABSTRACT: It is recognized that exercise produces abnormally large increases in pulmonary artery pressure in patients with pulmonary vascular disease as a consequence of a variety of disorders, but the relationship between pressure and cardiopulmonary exercise performance is poorly understood. This lack of understanding is due (in part) to difficulty making measurements of pulmonary haemodynamics using conventional fluid filled catheters. This article seeks to improve understanding by comparing variables measured during formal exercise testing with simultaneous measurements of pulmonary artery pressure using a micro-manometer tipped catheter.

Ten patients with suspected pulmonary hypertension were studied using a micromanometer tipped pulmonary artery catheter, during cardiopulmonary exercise testing.

Ventilatory equivalents for oxygen and carbon dioxide correlated with the pulmonary artery pressure measured on exercise, but oxygen pulse and oxygen uptake did not. Ventilatory equivalents, noninvasively measured during exercise, may merit further study as potential surrogates of pulmonary artery pressure and hence be useful in identifying individuals at risk of developing pulmonary hypertension. Eur Respir J 2000; 16: 282-287.
\end{abstract}

\begin{abstract}
*Scottish Pulmonary Vascular Unit, Dept of Respiratory Medicine; "Clinical Research Initiative, University of Glasgow, Dept of Cardiology; and "Pulmonary Function Laboratory, Dept of Respiratory Medicine, West Glasgow Hospitals University NHS Trust, Western Infirmary, Glasgow. ${ }^{*}$ Centre for Rheumatic Diseases, Glasgow Royal Infirmary University NHS Trust, Royal Infirmary, 84 Castle Street, Glasgow. ${ }^{\S}$ Academic Unit, Dept of Cardiology, University of Hull, Castle Hill Hospital, Kingston upon Hull.
\end{abstract}

Correspondence: A.J. Peacock, Scottish Pulmonary Vascular Unit, Dept. of Respiratory Medicine, West Glasgow Hospitals University NHS Trust, Western Infirmary, Glasgow G11 6NT. Fax: 441412116334.

Keywords: Cardiac catheterization cardiopulmonary exercise testing pulmonary hypertension

Received: March 71999 Accepted after revision April 282000 Supported by a British Heart Foundation Project Grant.
Conventional methods of measurement in the pulmonary circulation may be invasive or noninvasive. Cardiac catheterization with fluid filled, pulmonary artery catheters remains the gold standard method of haemodynamic measurement and is usually performed in supine patients at rest.

In the past, secondary pulmonary hypertension has not been regarded as an important target for therapy and therefore few patients required multiple haemodynamic measurements. It is now realized that secondary pulmonary hypertension is relatively common and is a particular problem in connective tissue disease [1]. Furthermore, new treatment options are available and prostacyclin and its derivatives have been shown to be beneficial long-term therapy for some patients [2], including those with severe pulmonary hypertension in association with connective tissue disease $[3,4]$. Thus many more patients now require repeated haemodynamic assessment.

While cardiac catheterization remains the assessment of choice, the increased demand on existing facilities suggests that additional methods of measurement might be useful.

Of particular interest in the study of the vasoreactivity of the pulmonary circulation is its response to the demands of exercise, when patients often report symptoms, and when abnormal levels of pulmonary artery pressure (PAP) may predict the subsequent development of pulmonary hypertension [5]. Stress testing of the pulmonary circulation can be performed with fluid filled, pulmonary artery catheters in the cardiac catheterization laboratory [6], or alternatively by Doppler echocardiography [7] but there are technical difficulties inherent in both techniques.

Patients with pulmonary vascular disease often have limited exercise tolerance. This may be partly due to their prolonged adaptation to, and recovery from, exercise because of the limitations to blood flow imposed by the central circulation. This results in a reduction in oxygen uptake $\left(V^{\prime} \mathrm{O}_{2}\right)$ despite a greater than normal increase in ventilation $\left(V^{\prime} \mathrm{E}\right)$. Such patients have an oxygen deficit (i.e. require to perform work using preformed energy sources) and therefore perform exercise at a biological disadvantage [8].

Previously a micro-manometer tipped pulmonary artery catheter has been used to measure PAP in fully ambulant patients, including during a formal cardiopulmonary exercise test [9]. This technique avoids some of the disadvantages mentioned previously and permits accurate pressure recording in exercising patients. In the present study gas exchange variables and PAP have been measured simultaneously during cardiopulmonary exercise testing using this catheter in a group of patients with suspected pulmonary hypertension.

\section{Hypothesis}

Correlations between gas exchange variables and pulmonary artery pressure, measured simultaneously during 
cardiopulmonary exercise testing were sought. It was reasoned that these variables might then merit further study as potential noninvasive surrogate markers of the PAP response to exercise.

\section{Methods and equipment}

\section{The catheter}

The catheter used in this study has been described in detail elsewhere [10], but briefly it is a 7-F solid micromanometer-tipped high-fidelity catheter designed for multiple use, (Gaeltech Ltd, Dunvegan, Isle of Skye, UK). Monitoring systems of this type are particularly suitable for pressure measurement in ambulant or exercising patients because of the micromanometer tip. Such systems are not new [11] and have been used previously in patients with pulmonary hypertension secondary to heart disease [12]. The catheter provides high fidelity signals of PAP but not cardiac output.

\section{Pulmonary artery pressure data recording}

Pressure data is recorded by a portable battery powered recorder (Type MPR/2, Gaeltech Ltd) before being downloaded to a desk top computer for storage and analysis (Mitsubishi Apricot Pentium 100; Mitsubishi PC Electric Division, Birmingham, UK). The recorder is worn over the patient's shoulder and is lightweight and compact (weighing $650 \mathrm{~g}$ and measuring $188 \times 137 \times 45 \mathrm{~mm}$ ) and is described fully elsewhere [9].

\section{Data analysis}

The analysis programme (Gaeltech Ltd) permits pulmonary artery pressure tracings to be matched accurately with periods of exercise testing. The average systolic, diastolic and mean pressures for periods of rest and during exercise are then calculated. Mean pressures are derived from the recorded pressure waveform. Point values are taken from the pressure trace every $0.03 \mathrm{~s}$ and then divided by the total time for which a mean pressure is required.
The standard deviations calculated from these measurements are small because the numbers of individual measurements are large.

\section{Cardiopulmonary exercise equipment}

All patients were exercised using the "Sensormedics VMax System" (Sensormedics, Yorba Linda, CA, USA) wearing an adult facemask (Hans Rudolph, inc. 7200, Kansas City, USA). The electromagnetically braked cycle ergometer was chosen over the treadmill because it is safer and can maintain a given work-rate despite fluctuations in the frequency of pedalling.

\section{Statistics}

All data are expressed as mean $\pm \mathrm{SD}$, unless otherwise stated. The strength of the correlation between the means was assessed by the Pearson correlation test. A p-value of $<0.05$ was considered to be statistically significant. Statistical analyses were carried out using the OXSTAT package for personal computers (Microsoft Corporation, Redmond, WA, USA).

\section{Patients and measurements}

\section{Patients}

This investigation was approved by West Glasgow Hospitals University NHS Trust Ethics Committee and all patients gave written, informed consent.

Ten patients were studied, of whom seven had connective tissue disease, as defined by immunopathological patterns (two with carcinosis, Reynaud's phenomenon, oesophageal involvement, sclerodactyly, and telandiectasia (CREST) syndrome, three with positive autoantibodies and an undefined connective tissue disease, one with rheumatoid arthritis and one with features suggestive of a scleroderma/systemic lupus erythematosis overlap syndrome). Three had presumed primary pulmonary hypertension according to National Institutes of Health (NIH) criteria. There were seven female and three male patients with mean age of 49 yrs (range 25-69 yrs) (table 1). All patients were considered capable of exercise at low workload on the cycle ergometer.

Table 1. - Patient demographics, diagnoses and baseline pulmonary function

\begin{tabular}{|c|c|c|c|c|c|c|}
\hline $\begin{array}{l}\text { Patient } \\
\text { No. }\end{array}$ & Age & Sex & Diagnosis & $\begin{array}{c}\text { FEV1 } \\
\text { L (\% pred) }\end{array}$ & $\begin{array}{c}\text { FVC } \\
\text { L (\% pred) }\end{array}$ & $\begin{array}{c}\mathrm{KCO} \\
\mathrm{mol} \cdot \mathrm{min}^{-1} \cdot \mathrm{Kpa}^{-1} \text { (\% pred) }\end{array}$ \\
\hline 1 & 36 & $\mathrm{~F}$ & CTD & $4.5(145)$ & $4.9(123)$ & $1.2(68)$ \\
\hline 2 & 62 & $\mathrm{~F}$ & CREST & $2.2(105)$ & $2.7(92)$ & $1.2(72)$ \\
\hline 3 & 67 & $\mathrm{~F}$ & CREST & $1.4(83)$ & $2.0(84)$ & $1.0(62)$ \\
\hline 4 & 69 & $\mathrm{~F}$ & CTD & $1.4(80)$ & $2.1(80)$ & $0.9(56)$ \\
\hline 5 & 40 & $\mathrm{~F}$ & SCL/SLE & $2.8(100)$ & $3.6(102)$ & $1.8(76)$ \\
\hline 6 & 56 & M & RA & $3.7(93)$ & $5.0(94)$ & $0.6(43)$ \\
\hline 7 & 25 & $\mathrm{M}$ & $\mathrm{PPH}$ & $3.9(95)$ & $5.1(107)$ & $1.5(77)$ \\
\hline 8 & 54 & $\mathrm{~F}$ & $\mathrm{PPH}$ & $2.6(119)$ & $3.2(113)$ & $1.1(66)$ \\
\hline 9 & 39 & M & $\mathrm{PPH}$ & $3.5(99)$ & $4.4(104)$ & $1.4(80)$ \\
\hline 10 & 41 & $\mathrm{~F}$ & CTD & $2.6(92)$ & $3.3(93)$ & $0.7(39)$ \\
\hline Mean \pm SD & $48(25-69)$ & & & $2.8 \pm 1.1(101.1 \pm 18.9)$ & $3.2 \pm 1.2(99.2 \pm 13.2)$ & $1.1 \pm 0.4(63.9 \pm 14.1)$ \\
\hline
\end{tabular}

M: male; F: female; CTD: connective tissue disease; CREST: calcinosis, Raynaud's phenomenon, oesophageal dysmotility, sclerodactyly, telangectasia; RA: rheumatoid arthritis. SCL/SLE: scleroderma/systemic lupus erythematosis overlap syndrome; PPH: primary pulmonary hypertension; FEV1: forced expiratory volume in one second; FVC: forced vital capacity; KCO: carbon monoxide transfer factor. 


\section{Measurements}

Routine investigations. Prior to cardiac catheterization routine investigations included electrocardiogram, pulmonary function testing, chest radiograph and Doppler echocardiography (Acuson 128 XP/10C, Acuson Ltd., Mount View. CA, USA). High-resolution computed tomography (CT) scanning of thorax was performed to exclude interstitial lung disease.

Cardiac catheterization. These patients were initially referred to the authors' centre for investigation of suspected pulmonary hypertension and were assessed according to our standard protocols. Conventional cardiac catheterization was therefore carried out in each case, using a balloon tipped, thermodilution, cardiac catheter of the Swan-Ganz type (Swan Ganz, 7-F, Thermodilution Catheter; Baxter Healthcare, Irvine, CA, USA).

Pressures were recorded in the right atrium, right ventricle and proximal pulmonary artery, and an estimate of pulmonary artery occlusion pressure was made with the catheter in the wedge position. Cardiac output was averaged over a minimum of three measurements using the thermodilution technique. In all patients the effects of exercise on pulmonary artery pressure was assessed by asking them to perform $3 \mathrm{~min}$ of straight leg raising. In the last $30 \mathrm{~s}$ of exercise, measurements of pulmonary artery pressure and cardiac output were repeated. Pulmonary artery occlusion pressure was not remeasured if the resting value had been normal, as is the authors' standard practice, as they believe that repeat measurement after exercise slightly increases the risk to the patient.

Immediately following this procedure the micromanometer-tipped pulmonary artery catheter was calibrated [13] and placed in the right or left proximal, pulmonary artery under fluoroscopic screening. A real time pressure trace was obtained to confirm satisfactory recording and an initial reference calibration performed [13]. The patient was then returned to the ward and continuous recording started.

Values quoted in this paper are means unless otherwise stated, calculated as described above.

Cardiopulmonary exercise testing. Formal exercise testing was performed after the micromanometer-tipped pulmonary artery catheter had been in place for almost $24 \mathrm{~h}$.

Protocol. Exercise was performed on the electromagnetic, cycle ergometer and consisted of a steady state exercise test at a workload of 30 Watts for a maximum of $8 \mathrm{~min}$. This relatively low workload was chosen as manageable, and likely to be below the anaerobic threshold, for this group of patients with expected limited exercise capacity. Constant work rate testing was performed because exercise of this type is particularly suitable for measuring cardiovascular, ventilatory and gas-exchange kinetics [14].

Baseline values were measured over 2 min with patients sitting at rest on the cycle, before pedalling at 30 watts for a maximum of $8 \mathrm{~min}$.

Cardiopulmonary exercise testing data. In each case breath by breath measurements of gas exchange were made. These included ventilation, tidal volume, respiratory rate, end tidal oxygen and carbon dioxide concentrations, oxygen saturations, $V^{\prime} \mathrm{O}_{2}$ and carbon dioxide production $\left(V^{\prime} \mathrm{CO}_{2}\right)$. From these measurements other variables were derived including oxygen pulse (oxygen uptake/heart rate), and the ventilatory equivalents for oxygen $\left(V^{\prime} \mathrm{E} / V^{\prime} \mathrm{O}_{2}\right)$ and carbon dioxide $\left(V^{\prime} \mathrm{E} / V^{\prime} \mathrm{CO}_{2}\right)$ i.e. the ratios of ventilation to oxygen uptake and carbon dioxide output respectively. During exercise the PAP was recorded continuously with the micro-manometer tipped pulmonary artery catheter.

\section{Results}

All the exercise variables presented are the mean of the values recorded for $1 \mathrm{~min}$ from the onset of the 4th min of exercise, on the assumption that 3 min of constant workload exercise must have elapsed before steady state gas exchange kinetics will have become established [15]. Pulmonary artery pressures given are the mean pressures measured during the same period.

Relationship of pulmonary artery pressure to noninvasive variables measured during cardiopulmonary exercise testing

PAP measured with the micromanometer-tipped pulmonary artery catheter during the 4th minute of steady state exercise at 30 watts correlated with $V^{\prime} \mathrm{E} / V^{\prime} \mathrm{O}_{2}(\mathrm{r}=0.78$, $\mathrm{p}=0.008)$, and $V^{\prime} \mathrm{E} / V^{\prime} \mathrm{CO}_{2}(\mathrm{r}=0.80, \mathrm{p}=0.005)$ (fig. 1, tables 2 and 3 ). There was no correlation between exercise PAP
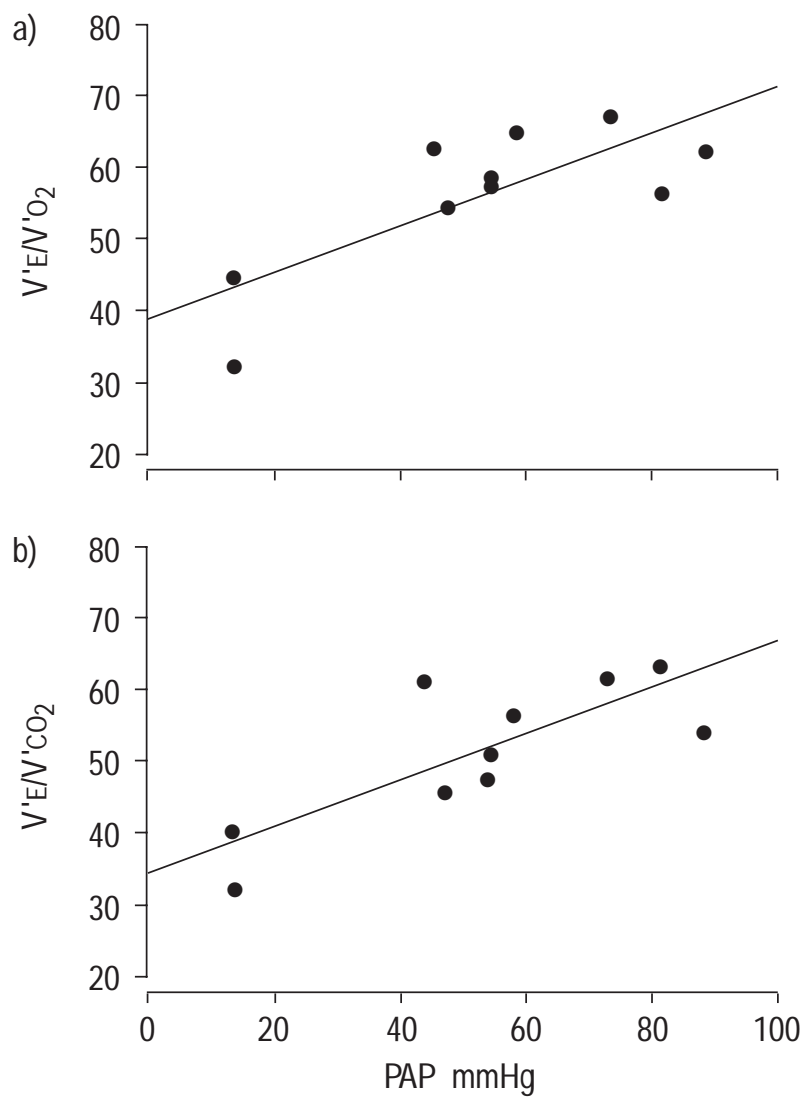

Fig. 1. - Ventilatory equivalents for a) oxygen $\left(V^{\prime} \mathrm{E} / V^{\prime} \mathrm{O}_{2}\right)$ and b) carbon dioxide $\left(V^{\prime} \mathrm{E} / V^{\prime} \mathrm{CO}_{2}\right)$ measured during cardiopulmonary exercise testing (at a workload of 30 Watts), from the onset of the 4th minute of steady state exercise, for one minute, are shown plotted against the mean pulmonary artery pressure (PAP) recorded simultaneously. There was a significant correlation between the mean PAP on exercise and the mean value for the ventilatory equivalents $\mathrm{r}=0.78, \mathrm{p}=0.008$ and $\mathrm{r}=0.80, \mathrm{p}=$ 0.005 for oxygen and carbon dioxide respectively. 
and other exercise testing variables including heart rate, oxygen pulse $\left(\mathrm{O}_{2}\right.$ pulse), oxygen uptake $\left(V^{\prime} \mathrm{O}_{2}\right)$ and exercise time; nor did baseline lung function (FEV1, FVC and $\mathrm{KCO}$, shown in table 1) correlate with PAP, at rest or during exercise. The values for PAP, at rest and on exercise, measured with both the fluid filled, and micromanometer-tipped, pulmonary artery catheters are shown in table 2. Patient 2 shows a considerable difference between resting and exercise measurements made with the two types of catheter. Patients 3 and 5 demonstrated a much higher PAP on exercise measured with the micromanometer-tipped catheter than during straight leg raising measured with the fluid filled pulmonary artery catheter. Conversely patient 6 achieved a lower PAP with the micromanometer-tipped catheter than fluid filled catheter.

Resting versus exercise measurements made with the fluid filled, pulmonary artery catheter

When patients were asked to perform three minutes of straight leg raising there was a correlation between resting and exercise values of mean PAP measured in the supine position using the fluid filled catheter $(\mathrm{r}=0.96, \mathrm{p}<0.001)$. The mean increase in pressure was $12.2 \pm 6.3 \mathrm{mmHg}$.

Resting versus exercise measurements made with the micromanometer tipped pulmonary artery catheter

When patients exercised on the cycle ergometer at a steady state workload of $30 \mathrm{~W}$ there was a correlation between resting (measured in the sitting position) and exercise values of mean PAP $(r=0.90, p=<0.001)$. The mean increase in pressure due to exercise was $9.6 \pm 10 \mathrm{mmHg}$.

Both resting and exercise measurements with the fluid filled catheter were made in the lying position, whereas with the micromanometer-tipped catheter both measurements were made in the sitting position. To determine whether this postural difference had influenced our results, PAP was also measured with the micromanometer tipped
Table 3. - Gas exchange variables recorded during the 4th minute of steady state exercise at $30 \mathrm{~W}$

\begin{tabular}{lcccrc}
\hline $\begin{array}{l}\text { Patient } \\
\text { No. }\end{array}$ & $\begin{array}{c}f_{\mathrm{c}} \\
\text { beats·min }\end{array}$ & $V^{\prime} \mathrm{E} / V^{\prime} \mathrm{O}_{2}{ }^{*} V^{\prime} \mathrm{E} / V^{\prime} \mathrm{CO}_{2}{ }^{*}$ & $\begin{array}{c}\mathrm{Oxygen}^{2} \\
\text { pulse }^{+} \\
\mathrm{mL} \cdot \text { beat }^{-1}\end{array}$ & $\begin{array}{c}V^{\prime} \mathrm{O}_{2} \\
\mathrm{~L} \cdot \mathrm{min}^{-1}\end{array}$ \\
\hline 1 & 112 & 45 & 40 & 14.8 & 1.65 \\
2 & 143 & 32 & 32 & 5.8 & 0.83 \\
3 & 83 & 54 & 47 & 2.8 & 0.23 \\
4 & 120 & 59 & 48 & 4.8 & 0.58 \\
5 & 140 & 62 & 61 & 6.8 & 0.95 \\
6 & 107 & 65 & 57 & 11.7 & 1.26 \\
7 & 116 & 57 & 51 & 7.4 & 0.85 \\
8 & 179 & 56 & 51 & 5.2 & 0.93 \\
9 & 101 & 67 & 63 & 12.3 & 1.24 \\
10 & 105 & 62 & 54 & 7.7 & 0.81 \\
\hline
\end{tabular}

*: ventilatory equivalents are the ratios of minute ventilation $\left(V^{\prime} \mathrm{E}\right)$ to oxygen uptake $\left(V^{\prime} \mathrm{O}_{2}\right)$ and carbon dioxide production $\left(V^{\prime} \mathrm{CO}_{2}\right)$ respectively; ${ }^{+}: V^{\prime} \mathrm{CO}_{2}$ divided by cardiac frequency $(f \mathrm{c})$.

pulmonary artery catheter in the lying position and compared with exercise in the sitting position. PAP measured supine with the micromanometer tipped pulmonary artery catheter did correlate with the pressure measured on exercise in the sitting position with the same catheter $(r=0.92$, $\mathrm{p}<0.001)$. The mean increase in pressure was $73 \pm 11.9$ $\mathrm{mmHg}$.

\section{Discussion}

Exercise: noninvasively measured variables of gas exchange and pulmonary artery pressure.

The presented study has shown that PAP measured during steady state exercise with the micromanometer tipped pulmonary artery catheter correlates with $V^{\prime} \mathrm{E} / V^{\prime} \mathrm{O}_{2}$ and $V^{\prime} \mathrm{E} / V^{\prime} \mathrm{CO}_{2}$, but not with $\mathrm{O}_{2}$ pulse, or $V^{\prime} \mathrm{O}_{2}$.

The PAP values represent the mean of more than 60 values. $V^{\prime} \mathrm{E} / V^{\prime} \mathrm{O}_{2}$ and $V^{\prime} \mathrm{E} / V^{\prime} \mathrm{CO}_{2}$ are also the mean of all the raw data for breath by breath values recorded for the same period of steady state exercise $(1 \mathrm{~min})$ so we believe

Table 2. - Mean pulmonary artery pressure (PAP) at rest and on exercise with the conventional (fluid-filled) and the micromanometer-tipped catheter (MM-tipped)

\begin{tabular}{|c|c|c|c|c|}
\hline \multirow[b]{2}{*}{ Patient No. } & \multicolumn{2}{|c|}{ Resting PAP (mmHg) (Cardiac outputs $\mathrm{L} \cdot \mathrm{min}^{-1}$ ) } & \multicolumn{2}{|c|}{ Exercise PAP $(\mathrm{mmHg})\left(\right.$ Cardiac outputs $\left.\mathrm{L} \cdot \mathrm{min}^{-1}\right)$} \\
\hline & Fluid filled & MM tipped & Fluid filled & MM tipped \\
\hline 1 & $13(5.4)$ & 13 & $14(7.0)$ & 14 \\
\hline 2 & $20(4.7)$ & 8 & $39(7.0)$ & 14 \\
\hline 3 & $40(3.4)$ & 29 & $56(4.4)$ & 48 \\
\hline 4 & $33(5.0)$ & 33 & $43(7.2)$ & 55 \\
\hline 5 & $47(5.2)$ & 45 & $65(5.4)$ & 46 \\
\hline 6 & $40(5.4)$ & 42 & $45(8.9)$ & 59 \\
\hline 7 & $54(5.0)$ & 42 & $61(6.8)$ & 55 \\
\hline 8 & $48(3.2)$ & 48 & $60(3.3)$ & 82 \\
\hline 9 & $55(3.8)$ & 73 & $70(5.7)$ & 74 \\
\hline 10 & $71(4.7)$ & 69 & $90(6.2)$ & 89 \\
\hline
\end{tabular}

Fluid filled: resting pressure and cardiac output measurements were made in supine subjects and are the mean of 6 beats, breath holding at functional residual capacity. Exercise pressure and cardiac output measurements were made during the last $30 \mathrm{~s}$ and 3 min of straight leg raising. MM tipped: resting pressure measurements in the sitting position on the exercise bike for 2 min immediately prior to the onset of exercise. Exercise values were measured from the onset of the 4th min of steady state exercise (at a workload of 30 Watts) for 1 min. 
the results are reliable. As far as the authors are aware, this is the first study to show that PAP on exercise correlates with simultaneously measured ventilatory equivalents for oxygen and carbon dioxide. It is the authors' belief that these abnormal ventilatory equivalents on exercise are a result of increased physiological dead space ventilation, which is a consequence of the reduction in pulmonary capillary blood flow due to high pulmonary artery pressure. These results are not surprising and have been predicted by others $[8,16]$ but it is surprising that correlation between exercise PAP and $V^{\prime} \mathrm{O}_{2}$ or $\mathrm{O}_{2}$ pulse was not seen. This may have been because the numbers of patients in this study was insufficient, or, more likely, because the chosen exercise protocol used too low a workload to allow these patients to demonstrate limitations in these variables and that a correlation would have been found between PAP and $V^{\prime} \mathrm{O}_{2}$,max. Another explanation may be that the abnormally high levels of PAP seen on exercise in some patients with pulmonary vascular disease, which limit increases in cardiac output, also mask the change in $\mathrm{O}_{2}$ pulse with exercise.

\section{Pulmonary haemodynamics during exercise and resting pulmonary function}

Resting lung function (FEV1, FVC and $\mathrm{KCO}$ ) did not correlate with exercise PAP in this study. Others have shown that lung function tests are often normal in pulmonary hypertension [17] of various aetiologies, suggesting that pulmonary artery pressure per se has no effect on lung function. The authors' patients had no radiological or clinical evidence of underlying lung disease, therefore it was not surprising that this group had virtually normal spirometry. There was a reduction in the value of group mean KCO that would be explained on the basis of their pulmonary hypertension which has also been described in pulmonary hypertension of a variety of causes [18]. Therefore, this reduced KCO might have been expected to correlate with exercise levels of PAP, but this was not the case. It would have been interesting to measure exercise $\mathrm{KCO}$ in this group of patients, but this was beyond the scope of the study.

\section{Resting versus exercise pulmonary haemodynamics}

The present study shows that resting PAP measured in the supine or sitting position predicts PAP on exercise. Again this is not surprising and has been shown previously with fluid filled, pulmonary artery catheters [19] though it has been found that this is not always the case in patients with milder degrees of pulmonary hypertension [9]. Pulmonary artery occlusion pressure was not remeasured after exercise if the resting measurement was normal for the reasons previously discussed. It is likely that wedge pressure would have risen on exercise [20,21].

In the current study, the change in pressure on exercise was not predicted by the resting value of PAP. Furthermore there are discrepancies in some patients between the values of PAP measured with the two types of catheter, which are not consistent (table 2). However, in each case the micromanometer tipped pulmonary artery catheter reading taken in the cardiac catheterisation laboratory was consistent with the measurement of PAP which had just been obtained with the conventional catheter. Patient 2 has results which are anomalous. This may be because these measurements were not made simultaneously and it has been noted previously that there are significant intra-individual variations in pulmonary artery pressure measured at different times [22]. Alternatively it may be that the cardiac catheterization pressure measurement does not reflect the true resting state. However these differences seem too great to be likely to have arisen physiologically and are more likely to have been due to technical error, probably with the zero levelling of the fluid filled pulmonary artery catheter.

Patients 3 and 5 have similar resting pressures measured with both types of catheter, but have much larger rises in pulmonary artery pressure on exercise when measured with the micromanometer-tipped catheter during the cardiopulmonary exercise test. These patients have moderate pulmonary hypertension and it is possible that the greater amount of work and greater pulmonary flow during the exercise test, when compared with simple straight leg raising, caused greater rises in pulmonary artery pressure. Patient 6 had severe rheumatoid arthritis and found cycling difficult. Consequently the rise in pulmonary artery pressure during the cardiopulmonary exercise test is less than that measured during straight leg raising.

Resting PAP measured with either fluid filled or micromanometer tipped, pulmonary artery catheters did not correlate with cardiac output measured by thermodilution with fluid filled, pulmonary artery catheters, either at rest or after three minutes of exercise (straight leg raising). Nor was there any correlation between exercise PAP (measured with the micromanometer-tipped pulmonary artery catheter) and the change in cardiac output from rest to exercise when measured with the fluid filled pulmonary artery catheter. However, a trend was observed in that patients with higher levels of PAP tended to have lower resting values of cardiac output. The small numbers of patients in this study and the low level of exercise achieved make the interpretation of these observations difficult.

\section{Conclusion}

It has been shown that pulmonary haemodynamics on exercise can be measured by micromanometer-tipped pulmonary artery catheters, and that these haemodynamics correlate with ventilatory equivalents for oxygen and carbon dioxide measured noninvasively during a simultaneous cardiopulmonary exercise test. Accurate measurements of pulmonary artery pressure on exercise in patients with mild resting pulmonary hypertension, or normal pulmonary artery pressure who are symptomatic on exercise, may be useful in identifying individuals at risk of developing pulmonary hypertension. This study suggests that ventilatory equivalents may merit further study as potential noninvasive surrogates of pulmonary artery pressure.

\section{References}

1. Battle RW, Davitt MA, Cooper SM, et al. Prevalence of pulmonary hypertension in limited and diffuse scleroderma. Chest 1996; 110: 1515-1519. 
2. McLaughlin VV, Genthner DE, Panella MM, Rich S. Reduction in pulmonary vascular resistance with longterm expoprostenol (prostacyclin) therapy in primary pulmonary hypertension. $N$ Engl J Med 1998; 5: 273-277.

3. De La Mata J, Gomez-Sanchez MA, Aranzana M, Gomez-Reino JJ. Long-term iloprost infusion therapy for severe pulmonary hypertension in patients with connective tissue diseases. Arthritis and Rheum 1994; 37 : $1528-1533$.

4. Humbert M, Sanchez O, Fartoukh M, Jagot J-L, Sitbon O, Simmonneau G. Treatment of severe pulmonary hypertension secondary to connective tissue diseases with continuous intravenous epoprostenol (prostacyclin). Chest 1998; 114: 80S-82S.

5. Weitzenblum E, Chaouat A, Oswald M. Pulmonary hypertension due to chronic hypoxic lung disease. In: Peacock AJ, ed. Pulmonary Circulation, a handbook for clinicians. London, Chapman and Hall, 1996; pp. 157-170.

6. Ikram H, Richards AM, Hamilton EJ, Nicholls MG. Continuous recording of pulmonary artery pressure in unrestricted subjects. Br Heart $J$ 1984; 51: 421-426.

7. Winslow TM, Ossipov M, Redberg RF, Fazio GP, Schiller NB. Exercise capacity and haemodynamics in systemic lupus erythematosis: a Doppler echocardiographic exercise study. Am Heart J 1993; 126: 410-414.

8. Sietsema KE. Oxygen uptake kinetics in response to exercise in patients with pulmonary vascular disease. $\mathrm{Am}$ Rev Respir Dis 1992; 145: 1052-1057.

9. Raeside DA, Chalmers G, Cleland J, Madhok R, Peacock AJ. Pulmonary artery pressure variation in patients with connective tissue disease: 24 hour ambulatory pulmonary artery pressure monitoring. Thorax 1998; 53: 857-862.

10. Gibbs SR, MacLachlan D, Fox KM. A new system for ambulatory pulmonary artery pressure recording. $\mathrm{Br}$ Heart $J$ 1992; 68: 230-235.

11. Levy RD, Cunningham D, Shapiro LM, Wright C, Mockus L, Fox KM. Continuous ambulatory pulmonary artery pressure monitoring. A new method using a transducer tipped catheter and a simple recording system. $\mathrm{Br}$ Heart J 1986; 55: 336-343.
12. Gibbs JSR, Keegan J, Wright C, Fox KM, Poole-Wilson PA. Pulmonary artery pressure changes during exercise and daily activities in chronic heart failure. $J$ Am Coll Cardiol 1990; 15: 52-61.

13. Gibbs JSR, Cunningham D, Sparrow J, Poole-Wilson PA, Fox KM. Unpredictable zero drift in intravascular micromanometer catheters during long term pulmonary artery pressure recording: implications for catheter design. Cardiovasc Research 1989; 2: 152-158.

14. Nery LE, Wasserman K, Andrews JD, Huntsman DJ, Hansen JE, Whipp BJ. Ventilatory and gas exchange kinetics during exercise in chronic airways obstruction. $J$ Appl Physiol 1982; 53: 1594-1602.

15. Sietsema KE, Daly JA, Wasserman K. Early dynamics of $\mathrm{O}_{2}$ uptake and heart rate as affected by exercise work rate. J Appl Physiol 1989; 67: 2535-2541.

16. Manier G, Castaing Y. Gas exchange abnormalities in pulmonary vascular and cardiac disease. Thorax 1994; 49: 1169-1174.

17. Gazetopoulos N, Salonikides N, Davies H. Cardiopulmonary function in patients with pulmonary hypertension. Br Heart J 1974; 36: 19-28.

18. Romano AM, Tomaselli S, Gualtieri G, et al. Respiratory function in precapillary pulmonary hypertension. Monaldi Arch Chest Dis 1993; 48: 201-204.

19. Lupi-Herra E, Sandoval J, Seoane M, Bialostozky D. The role of hydralazine therapy for pulmonary hypertension of unknown cause. Circulation 1982; 65: 645-650.

20. Abdel Kafi S, Melot C, Vachiery JL, Brimioulle S, Naeije R. Partitioning of pulmonary vascular resistance in primary pulmonary hypertension. JACC 1998; 31: 13721376.

21. Janicki JS, Weber KT, Likoff MJ, Fishman AP. The pressure flow response of the pulmonary circulation in patients with heart failure and pulmonary vascular disease. Circulation 1985; 72: 1270-1278.

22. Rich S, Martinez J, Lam W, Rosen K. Captopril as treatment for patients with pulmonary hypertension. Problem of variability in assessing chronic drug treatment. $\mathrm{Br}$ Heart J 1982; 48: 272-277. 